\title{
TURISMO EN ESPAÑA, MÁS ALLÁ DEL SOL Y LA PLAYA. EVOLUCIÓN RECIENTE Y CAMBIOS EN LOS DESTINOS DE LITORAL HACIA UN TURISMO CULTURAL
}

\author{
Gemma Cànoves Valiente \\ Josep Ma Prat Forga \\ Asunción Blanco Romero \\ Departamento de Geografía \\ Universitat Autònoma de Barcelona \\ gemma.canoves@uab.cat ; josepmaria.prat@uab.cat ; Asunción.blanco@uab.cat
}

\section{RESUMEN}

En muchos destinos maduros, el tradicional turismo de litoral necesita productos innovadores que le ayuden a su regeneración. Uno de ellos es el turismo cultural. Así, en este trabajo, después de conocer la situación actual del turismo, en base a los datos disponibles, se profundiza en el caso del turismo cultural en España, entendido como un turismo complementario en los destinos de litoral, y se demuestra que, efectivamente, el país también se está posicionando como un destino internacional de turismo cultural que ayuda a la revitalización de unos destinos tradicionalmente orientados al sol y la playa.

Palabras clave: Turismo, España, turismo cultural, sol y playa, revitalización turística.

\section{ABSTRACT}

In many mature destinations, the traditional tourism of littoral needs innovative products that help him to his regeneration. One of them is the cultural tourism. In this work paper, after knowing the current situation of the tourism, from data information, it is deepened in case of the cultural tourism in Spain, understood as a complementary tourism in the

Fecha de recepción: octubre 2013.

Fecha de aceptación: junio 2015. 
destinations of littoral, and there is demonstrated that, really, the country also is positioned as an international destination of cultural tourism that helps the regeneration of a destinations traditionally orientated to the sun and the beach.

Keywords: Tourism, Spain, cultural tourism, sun and beach, innovation in tourism.

\section{INTRODUCCIÓN Y OBJETIVOS}

En España, el turismo continúa siendo una actividad económica en pleno crecimiento, dado que a pesar de la crisis económica actual, el país se ha situado en el año 2013 como tercero del mundo en llegadas de visitantes, recibiendo 100,33 millones. De ellos, 60,66 millones eran turistas internacionales (el 60,5\% de las entradas) y 39,67 millones excursionistas -no pernoctaban en el país-, es decir el 39,5\% restante (según datos provisionales de FRONTUR-2013, extraídos de la Subdirección General de Conocimiento y Estudios Turísticos - Ministerio de Industria, Energía y Turismo).

Este constante flujo de llegadas se puede explicar por las crisis políticas de algunos países de nuestro alrededor que son competidores del turismo de sol y playa, como Túnez, Egipto o la misma Grecia. Así, por ejemplo, aunque Grecia en 2012 recibió 15,5 millones de turistas internacionales, ello representó un descenso del 5,5\% respecto al año 2011. (OMT, 2014). Sin embargo, esta no es la única explicación, Turquía recibió 35,7 millones de turistas en 2012 (lo que significó un aumento del 3\% respecto al año anterior) o Croacia 10,4 millones y representa un crecimiento del 4,5\%. A su vez, otros países del mismo entorno geográfico mantuvieron o aumentaron sus cifras, como Italia, que recibió 46,3 millones (con un crecimiento del 0,5\% respecto al 2011), Marruecos con 9,4 millones (un incremento del 0,3\%) o Túnez 5,9 millones (un aumento del 24,4\%). (OMT, 2014).

La estrategia de muchos destinos turísticos litorales en fase de estancamiento-agotamiento de su ciclo de vida turístico, en base a Butler (1980) y como ya confirmó Priestley (2007), es configurar ofertas complementarias al tradicional producto de sol y playa, orientadas a satisfacer los cambios en el sector y dar cabida a las nuevas motivaciones de unos turistas que transforman el viaje en una experiencia vital, compuesta por varios subproductos de ocio y recreación. (Bonet, 2003; Williams y Buswell, 2003).

En España uno de los productos que han adquirido mayor relevancia en los últimos diez años es el turismo cultural, que abarca un amplio abanico de actividades. El turismo cultural, tal como apunta Richards (1996), se basa en la valorización de los recursos patrimoniales de un territorio, sean elementos tangibles (como los museos) o intangibles (como el estilo de vida), por lo que, como para cualquier otro tipo de turismo, se trata de una experiencia. Además, se le considera un «gozo itinerante», un «gozo intelectual» y un «gozo personal», ya que el turista cultural disfruta de la experiencia a medida que aprende y experimenta la cultura que descubre.

En estos últimos años se ha producido un cambio en la percepción de la cultura, que ha pasado de ser una mera exposición descriptiva de unos elementos patrimoniales a ser un vehículo para conocer la manera de vivir de una sociedad y una época, lo que ha producido una ampliación del campo de acción del turismo cultural. Si antes se dirigía a un público cultivado y se refería a la «alta cultura», es decir a las bellas artes, principalmente, hoy en día, nos encontramos con un turismo omnipresente y omnipotente. (Richards, 1996). El mismo 
autor atribuye este cambio a una «culturización» de la sociedad, es decir, un incremento del nivel de educación que conduce a un mayor consumo de los productos culturales, produciendo un alto grado de satisfacción en sus consumidores, ayudando a desestacionalizar la demanda, fidelizando a los consumidores y aumentando la potencialidad del destino hasta llegar a situarlo como un atractivo turístico-cultural de interés. (Prat y Cànoves, 2012).

A nuestro entender el modelo de turismo en España debe apostar por la reinvención y la resiliencia. La reinvención para, a partir del turismo cultural, poner en valor los territorios colindantes a los espacios litorales, y la resiliencia de los destinos para resistir y reinventarse como espacios turístico-culturales. Este modelo de crecimiento turístico, sostenible en el tiempo y en la valorización de los recursos culturales, es el que ha seguido Francia desde el siglo XVIII, la prueba de su éxito es que este país sigue siendo la primera destinación turística y le ha permitido tener un turismo constante y menos depredador del territorio.

Así, el presente artículo, a partir de la evolución del turismo tradicional en España, tiene como objetivo conocer la situación actual y las perspectivas del turismo cultural en España, entendido como un turismo complementario a la consolidación o revitalización, según los casos, de los destinos maduros de nuestro litoral, dotándolos de significado y experiencia. De este modo, la hipótesis que se pretende demostrar es que frente a la consolidación del turismo de sol y playa, sin duda un producto incuestionable, España también se está posicionando como un destino internacional de turismo cultural, que ayuda a la revitalización de los destinos de litoral, tradicionalmente orientados al sol y la playa.

En base a estos objetivos, en primer lugar se explica la metodología utilizada y se presentan los principales datos estadísticos sobre la evolución del turismo y situación actual, a nivel mundial y europeo. Seguidamente, se analiza la evolución del turismo en España y, en particular, el turismo de litoral y el turismo cultural. A continuación, debido a la amplitud del tema, el presente trabajo se centra en analizar el impacto de dos atracciones culturales cercanas a grandes zonas litorales. Una, el complejo monumental de la Alhambra y del Generalife (en Granada), cerca de la Costa del Sol. Otra, el Teatro-Museo de Dalí (en Figueres), cerca de la Costa Brava.

\section{METODOLOGÍA}

Este trabajo se ha apoyado en datos de los institutos estadísticos oficiales de España (Instituto Nacional de Estadística-INE) y de Francia (Institut National de la Statistique et des Études Économiques-INSEE), así como de diversos organismos oficiales de turismo, como la Organización Mundial de Turismo (OMT) o el Instituto de Estudios Turísticos (IET).

También se han consultado los resultados de un cuestionario estructurado ( «I-Test Overall Results»), que realizó en 2009 la Federación Internacional del Automóvil (FIA) a 9.041 personas de 38 países con el objetivo de conocer los principales factores que se tuvieron en cuenta en el proceso de elección de un destino turístico. Dicha muestra tiene un margen de error de $\pm 1,05 \%$, para un nivel de confidencia del $95,5 \%$ (2 sigmas) en el caso de máxima indeterminación ( $\mathrm{p}=\mathrm{q}=50 \%)$. El 76,5\% de las respuestas provinieron de Europa, el 11,1\% de Asia Central y del Este, y el resto de África, Asia Occidental, Oceanía y América. El 61,3\% eran hombres y el 38,7\% mujeres, con una edad media de 45,6 años (con una desviación estándar de 13,6).

A continuación, para el análisis de las dos atracciones turísticas aquí analizadas (la Alhambra y el Teatro-Museo Dalí), se han obtenido datos estadísticos, en el primer caso, del 
informe «Datos de la actividad turística, educativa y cultural en el conjunto monumental de la Alhambra y Generalife. Año 2012», editado por el Patronato de la Alhambra y Generalife (2013) y de los resultados de una encuesta presentada en el mismo informe y realizada en el mismo año a 2.023 visitantes de este conjunto monumental, con un nivel de confianza del $95 \%$ y un error muestral de $\pm 5 \%$. En cuanto al Teatro-Museo Dalí, los datos se han obtenido de la «Memoria 2012» (Fundación Gala-Dalí, 2013) y de los resultados de una encuesta efectuada en el 2012, y presentada en el mismo informe, a 2.165 visitantes de dicho museo, con un nivel de confianza del $95 \%$ y un error muestral de $\pm 5 \%$.

\section{EVOLUCIÓN DEL TURISMO MUNDIAL}

El turismo a nivel mundial ha crecido progresivamente en estas últimas décadas, llegando a los 1.087 millones de practicantes en 2013, lo que representa un incremento del $5 \%$ sobre el año anterior (Kester, 2014) (figura 1). Estos resultados son especialmente significativos si se tienen en cuentan las previsiones de la OMT, que en enero de 2013 estimaba un crecimiento para dicho año entre el $3 \%$ y el $4 \%$, de modo que se han superado ampliamente las cifras inicialmente previstas.

Figura 1

EVOLUCIÓN DE LAS LLEGADAS DE TURISMO INTERNACIONAL

(En Millones de Turistas) (1995-2013)

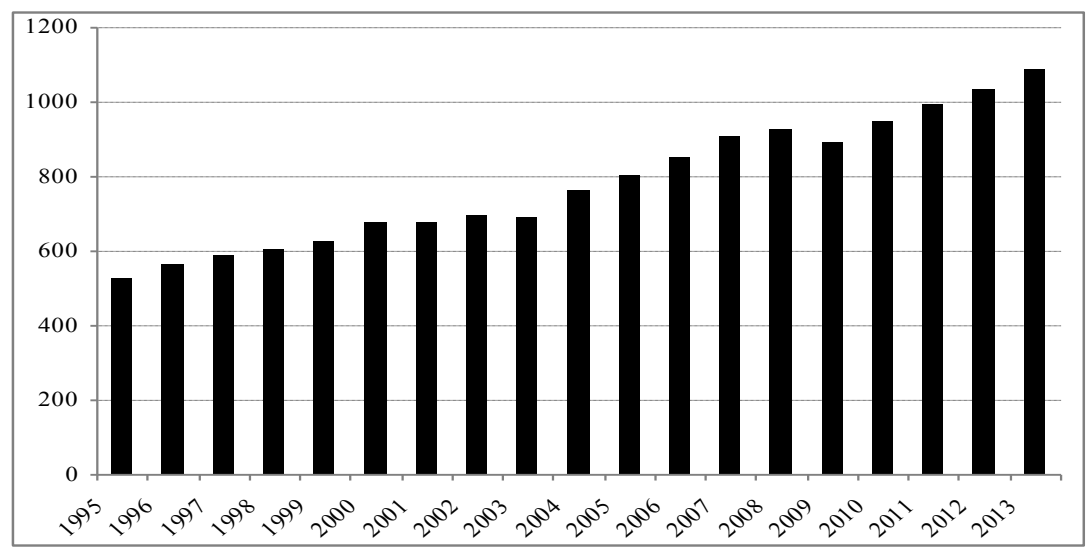

Fuente: OMT, 2014.

Para los próximos años, la previsión de la OMT es que continúe esta tendencia creciente, con un aumento entre el 4\% y el 4,5\% en el año 2014, llegándose a los 1.800 millones de turistas internacionales en el año 2030. Sin embargo, la OMT también estima que entre 2010 y 2030 (figura 2), las llegadas internacionales a los destinos emergentes crezcan el doble que en los destinos más tradicionales, con un 4,4\% de incremento anual en el primer caso y un 2,2\% en el segundo. De esta manera, si se tiene en cuenta que la cuota de mercado de las economías emergentes ha 
pasado del $30 \%$ en 1980 al $47 \%$ en 2012, se prevé alcanzar el 57\% en 2030, lo que equivale a más de mil millones de llegadas de turistas internacionales a dichas regiones. (Kester, 2014).

Figura 2

PROYECCIÓN DE LAS LLEGADAS DE TURISMO INTERNACIONAL (EN MILLONES DE TURISTAS)

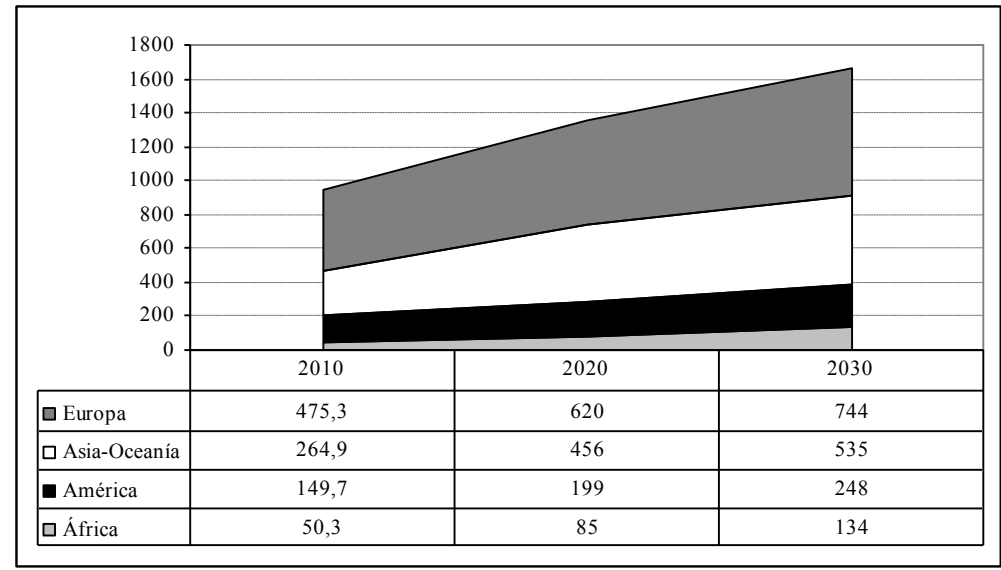

Fuente: OMT, 2014; Kester, 2014

Tradicionalmente, los principales mercados emisores del turismo internacional han sido las economías más avanzadas de Europa, América y Asia. Sin embargo, también los países con economías emergentes han experimentado un elevado crecimiento en los últimos años. En 2012, los turistas chinos gastaron 102.000 millones de dólares norteamericanos en viajes internacionales, lo que representa multiplicar por ocho el gasto realizado en 2000. Dicho incremento se debió al aumento de las rentas disponibles de la población china, la disminución de las restricciones para viajar al exterior y la revalorización de su moneda. Aún así, Europa sigue siendo la principal región emisora de turistas del mundo (con el $52 \%$ de las llegadas de turistas internacionales en 2013), frente al 23\% de Asia-Pacifico y el $16 \%$ de América, mientras que, por países, Francia ocupa el liderazgo mundial seguida por EEUU, China, España e Italia. (OMT, 2014).

Los ingresos por este concepto en 2012 crecieron el 11,74\% respecto al año anterior (un $4 \%$ en términos reales), alcanzando los 837.000 millones de euros. Por regiones, Asia y el Pacifico, América y África aumentaron sus ingresos interanuales alrededor del 6\%, mientras que Europa lo hizo el 2,3\%. Por países, la primera posición fue para EEUU, que obtuvo unos ingresos de 126,2 millones de dólares norteamericanos, doblando a España (segundo país del ranking), que ingresó 55,9 millones, por delante de Francia, China y Macao (China). (OMT, 2014). Con ello se demuestra que no hay una total correspondencia entre llegadas de turistas y los ingresos obtenidos por este concepto (tabla 1).

En el caso de Europa los resultados fueron especialmente destacables, teniendo en cuenta las persistentes dificultades económicas existentes en algunos países. Los ingresos por turismo internacional alcanzaron los 356.000 millones de euros (el 43\% del total mundial). En ello influyeron dos acontecimientos deportivos de gran resonancia mundial, el campeonato europeo 
de futbol de la UEFA (celebrado en Polonia y Ucrania) y los Juegos Olímpicos de Londres. Estos eventos deportivos impulsaron los ingresos por turismo en los tres países, mientras que la repercusión sobre las llegadas se limitó a Polonia (+11\%) y Ucrania (+7\%). (OMT, 2014).

Tabla 1

PRINCIPALES PAÍSES RECEPTORES DE TURISTAS INTERNACIONALES (Años 2011 Y 2012)

\begin{tabular}{|c|c|c|c|c|c|c|c|}
\hline \multicolumn{4}{|c|}{$\begin{array}{l}\text { Llegadas turistas internacionales } \\
\text { (en millones) }\end{array}$} & \multicolumn{4}{|c|}{$\begin{array}{l}\text { Ingresos por turismo internacional } \\
\text { (miles de millones \$ USA) }\end{array}$} \\
\hline & & 2011 & 2012 & & & 2011 & 2012 \\
\hline 1 & Francia & 81,6 & 83 & 1 & EEUU & 115,6 & 126,2 \\
\hline 2 & EEUU & 62,7 & 67 & 2 & España & 59,9 & 55,9 \\
\hline 3 & China & 57,6 & 57,7 & 3 & Francia & 54,5 & 53,7 \\
\hline 4 & España & 56,2 & 57,7 & 4 & China & 48,5 & 50 \\
\hline 5 & Italia & 46,1 & 46,4 & 5 & Macao (China) & 38,9 & 43,7 \\
\hline
\end{tabular}

Fuente: OMT, 2014.

Si nos fijamos en Francia, el primer país turístico del mundo según el número de turistas internacionales recibidos (83 millones en 2012, con una estancia media de 6,9 días), podemos observar que ha mantenido una progresión constante en los últimos años (77,6 millones en 2010; 81,5 millones en 2011; 83 millones en 2012), siendo en este último año el 83,4\% europeos. (INSEE, 2014). Hay que tener en cuenta que muchos de los visitantes extranjeros, sean excursionistas o turistas, van a Francia por motivos primordialmente profesionales o por compras, mientras que los que lo hacen fundamentalmente por ocio y vacaciones no llegan al $50 \%$. (TNS-SOFRES, 2008). Pero Francia no solamente es líder en turistas internacionales sino que también lo es en la recepción de excursionistas. Así, en 2012 llegaron 115,4 millones (un 2,5\% menos que el año anterior). Además, la tradicional estacionalidad veraniega se ha minimizado, ya que casi el $50 \%$ de los franceses mayores de quince años realiza una parte de sus vacaciones durante el invierno, permaneciendo el $90 \%$ en el propio país. (Dauphin et al., 2007).

Sin embargo, esta posición de liderazgo mundial solamente generó unos ingresos de 53.700 millones de dólares norteamericanos (-1,4\% respecto al año anterior), situándose por este concepto detrás de EEUU (116,100 millones) y España (59.900 millones). (INSEE, 2014). Esta circunstancia se debe a que, por una parte, el 16,86\% de turistas estaba en tránsito hacia otros países (especialmente durante la temporada de verano), por lo que solamente 69 millones tuvieron Francia como destino principal. Por otra parte, las estancias medias fueron de una semana, por lo que son inferiores a las realizadas en otros destinos, como ocurre en España, donde los turistas extranjeros hacen estancias medias de dos semanas. (Antczak y Le Garrec, 2008).

\section{SITUACIÓN DEL TURISMO EN ESPAÑA}

En el año 2013, llegaron a España 100,3 millones de visitantes (un 2,24\% más que en el año anterior), de los que 60,66 millones eran turistas (con una estancia media de ocho noches) y 39,66 millones eran excursionistas. (FRONTUR, 2014). Además, los residentes en el propio país realizaron 153 millones de desplazamientos internos por motivos de ocio 
y recreación, lo que significa una disminución del 2,2\% respecto al año anterior. (FAMILITUR, 2014). En el gráfico siguiente (figura 3) puede verse la evolución de dichos turistas durante el período 2005-2013. INTERNOS POR TURISMO DE LOS PROPIOS RESIDENTES (2005-2013)

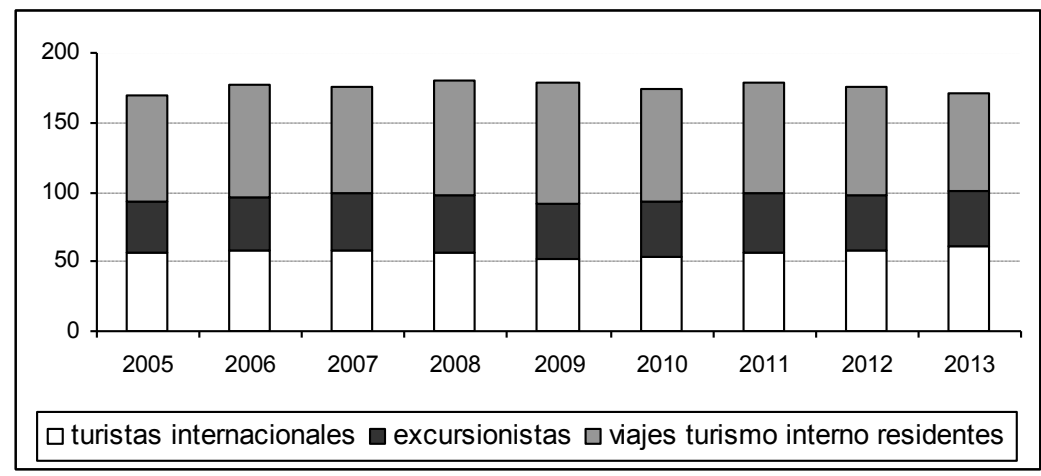

Fuente: FRONTUR, 2014; FAMILITUR, 2014.

La evolución de los turistas presentó hasta 2006 unas tasas de variación interanual positivas, que se desaceleraron en el año 2007 y en los periodos 2009-2010 y 2012-2013. La cantidad máxima de turistas fue en el 2008 (con 97,7 millones de llegadas y 82 millones de desplazamientos de turismo interno), aunque los mayores incrementos interanuales se produjeron en los años 2006 (el 4,31\%) y 2011 (el 2,93\%). El mayor descenso se ha producido en el año 2013 (el -3,07\%), donde las llegadas de visitantes, especialmente turistas, no han podido compensar la reducción del turismo interno, uno de los claros efectos de la situación de crisis económica en España. En el año 2014 se ha vuelto a las cifras de 2005, pero con mayor peso de las llegadas de turistas extranjeros, cuando en el año 2013 se alcanzó el máximo número de llegadas de estos turistas (60,66 millones). De ellas, el 86,6\% vinieron principalmente por motivos de ocio y vacacionales, mientras que el $6,7 \%$ fue por actividades relacionadas con el trabajo, los negocios, ferias o congresos, el 3,8\% por temas personales (familiares, compras, etc.) y el resto por estudios. En cualquier caso, los alojamientos predominantes fueron los hoteles y apartamentos turísticos (el 64,4\%), seguidos por las viviendas gratuitas (familia, amigos) (el 19,3\%) y las viviendas alquiladas (el 10,4\%). (FRONTUR, 2014).

Los turistas internacionales recibidos en 2013 eran mayoritariamente europeos, entre ingleses (14,3 millones), alemanes ( 9,8 millones) y franceses ( 9,5 millones) se contabilizaron el 55,5\% de las llegadas; y añadiendo italianos y holandeses se llegó a los 39,6 millones, es decir, el 65,2\% de las llegadas de este tipo de turistas a España. (FRONTUR, 2014). En cuanto a los destinos receptores, predominó Cataluña (el 25,70\% de las llegadas), seguida por las Islas Baleares (el 18,30\%), las Islas Canarias (el 17,50\%), Andalucía (el 17,50\%), la Comunidad Valenciana (el 9,8\%) y la Comunidad de Madrid (el 7\%). (Detalle en la figura 4). Cabe destacar, que entre las tres comunidades que más turistas internacio- 
nales recibieron (Cataluña, Baleares y Canaria) se contabilizaron el 61,5\% de las llegadas; y entre las seis primeras (las tres anteriores más Andalucía, Valencia y Madrid) el 91,3\%. (FRONTUR, 2014). A nivel territorial, la mayor ocupación turística se produjo, como es habitual en las zonas litorales, especialmente en los meses de verano, excepto en las Islas Canarias, donde la ocupación es estable a lo largo de todo el año. (IET, 2013).

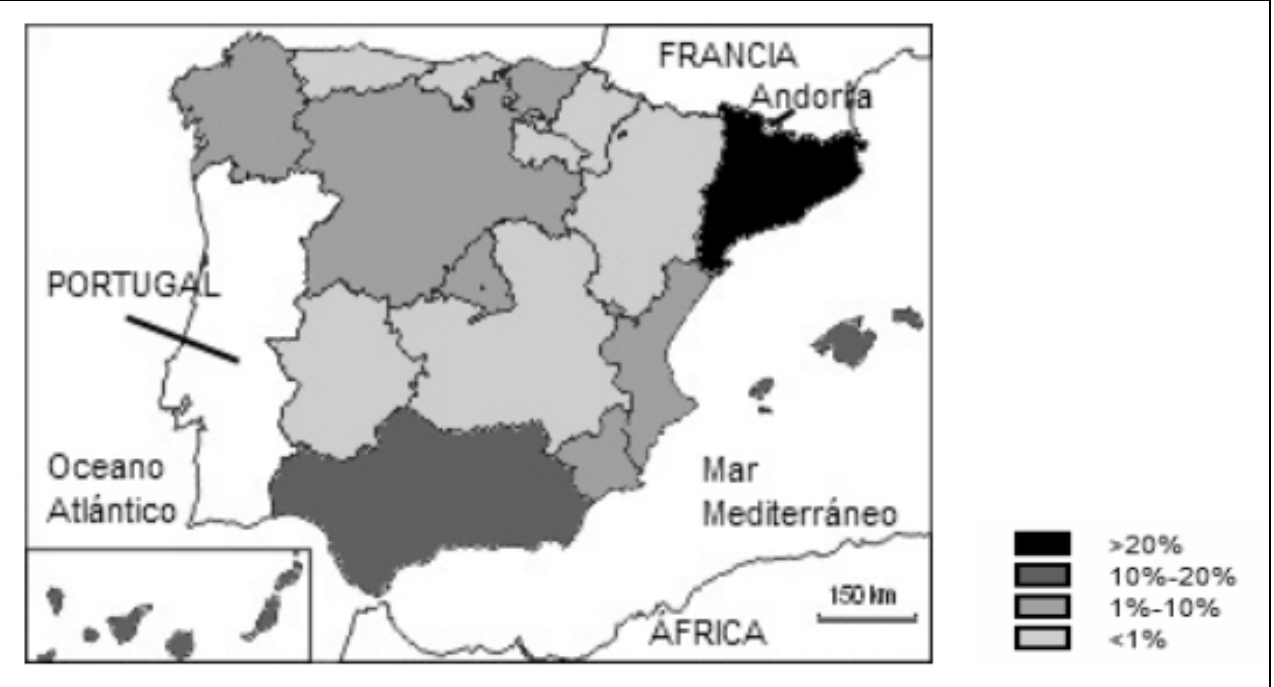

Fuente: Elaboración propia a partir de FRONTUR, 2014

El perfil medio del turista internacional que llega a España es el de una persona entre 25 y 44 años de edad, asalariada, con un cargo profesional medio y con estudios superiores, que viene en pareja por motivos de ocio y recreación, por vía aérea y que suele residir en establecimientos hoteleros, según datos del Instituto de Estudios Turísticos. (IET, 2013). Su grado de satisfacción con la visita realizada es alto (un 8,5 sobre 10) y presenta una alta fidelidad al destino, ya que el $83,5 \%$ repite el viaje y el $62 \%$ piensa volver a hacerlo en los próximos doce meses. Sin embargo hay disparidades según el país de origen, destacando la fidelidad de los portugueses, ya que el 93\% repiten el viaje a España. (HABITUR, 2012).

El gasto que realizaron estos turistas en su visita a España en 2013 fue de 59.081 millones de euros, lo que representó un incremento interanual del 9,6\%. (EGATUR, 2014). En la figura 5 se puede apreciar la evolución de dicho gasto durante el período 2004-2013, así como el gasto de los excursionistas y de los turistas internos, ambos muy inferiores al anterior, aunque todos los grupos presentan una clara tendencia al alza en valores absolutos.

Por comunidades autónomas de destino de los turistas internacionales, las que tuvieron mayores ingresos por este concepto fueron las mediterráneas, las isleñas y Madrid, tal como se puede apreciar en la figura 6. Así, Cataluña fue el destino donde mayor gasto realizaron 
estos turistas (59,1 millones de euros), seguido por Canarias (11,7 millones de euros), Baleares (10,7 millones de euros), Andalucía (8,4 millones de euros), Valencia (5,2 millones de euros) y Madrid (5 millones de euros). (EGATUR, 2014).

Figura 5

EVOLUCIÓN DEL GASTO DE LOS TURISTAS EN ESPAÑA (2004-2013)

(EN MILLONES DE EUROS)

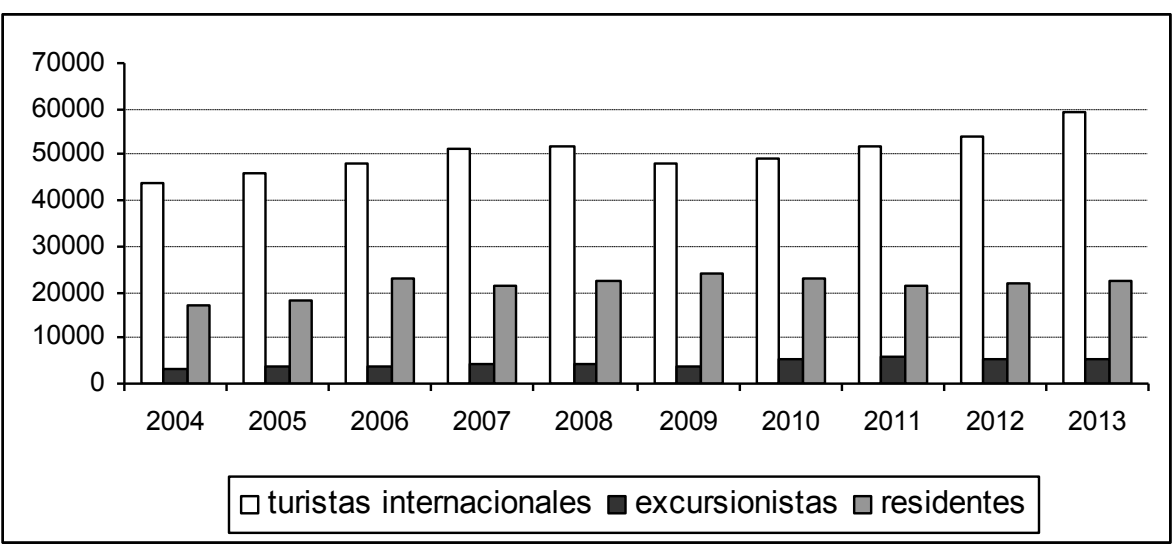

Fuente: EGATUR, 2014; FAMILITUR, 2014.

Figura 6

GASTOS DE LOS TURISTAS INTERNACIONALES POR COMUNIDADES AUTÓNOMAS DE DESTINO (2013) (EN MILLONES DE EUROS)

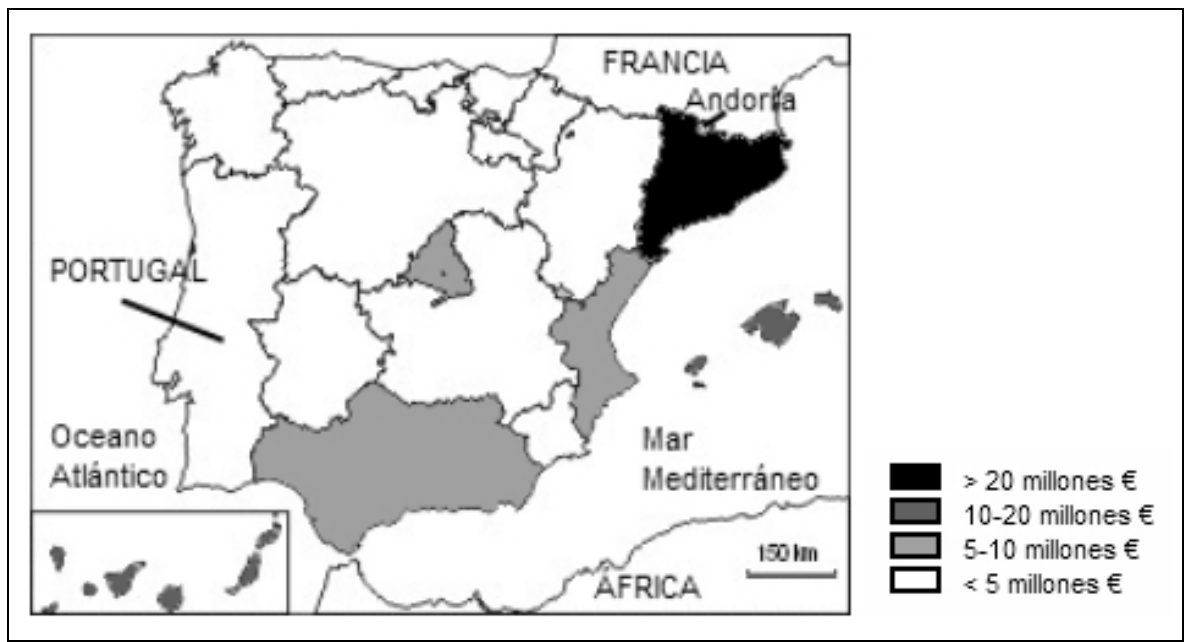

Fuente: elaboración propia a partir de EGATUR, 2014. 
Por persona, el gasto medio de los turistas internacionales en el año 2013 fue de 976 euros durante su estancia en España, aunque con notables disparidades según su lugar de origen. Los provenientes de EEUU realizaron un gasto medio de 2.069 euros por persona durante su estancia. Por contra, el gasto medio por persona de los excursionistas a lo largo de su estancia en España fue sensiblemente inferior (130,3 euros), al igual que el gasto turístico interior (149,6 euros). Sin embargo, la evolución de este gasto medio en el período 2004-2013 ha ido aumentando en los tres perfiles de turistas. (Ver figura 7).

Figura 7

EVOLUCIÓN DEL GASTO MEDIO POR PERSONA DE LOS TURISTAS

DURANTE SU ESTANCIA (2004-2013) (EN EUROS)

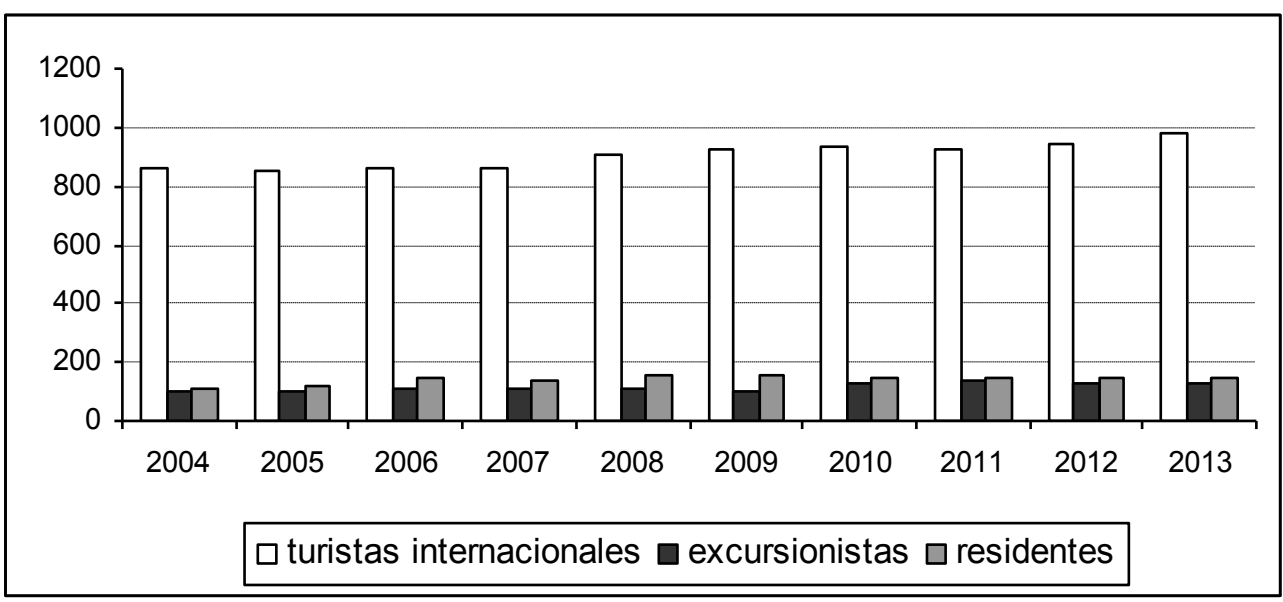

Fuente: EGATUR, 2014; FAMILITUR, 2014.

Si nos fijamos en los países que han aportado mayor número de turistas extranjeros, solamente los alemanes (con 987 euros gastados durante su estancia en España) han superado el gastos medio por cada turista internacional 2013 (976 euros), mientras que los holandeses (917 euros por persona), británicos (846 euros), italianos (747 euros) y franceses (624 euros) no han llegado al gasto medio. Sin embargo, según el lugar de destino, dicho gasto fue superado por los turistas que se desplazaron a Asturias (1.345 euros por persona), Castilla-La Mancha (1.302 euros por persona), la Comunidad de Madrid (1.185 euros por persona), Islas Canarias (1.099 euros por persona), Andalucía (1.066 euros por persona), Aragón (991 euros por persona) y Murcia (987 euros por persona). (EGATUR, 2014) (figura 8).

Por su parte, el gasto medio diario realizado por cada turista internacional durante su estancia en España fue de 109 euros en el año 2013, lo que representa un incremento del $3,3 \%$ respecto al año anterior. (EGATUR, 2014). Es evidente que los turistas internacionales son un elemento clave para la economía del sector, ya que su gasto medio es superior al del turista nacional o excursionista. Seguidamente se presenta un gráfico (figura 9) donde se aprecia la creciente evolución de dicho gasto medio diario desde 2004. 
Figura 8

GASTO MEDIO POR PERSONA DURANTE SU ESTANCIA EN ESPAÑA DE CADA TURISTA INTERNACIONAL POR COMUNIDADES AUTÓNOMAS DE DESTINO (2013)(EN EUROS)

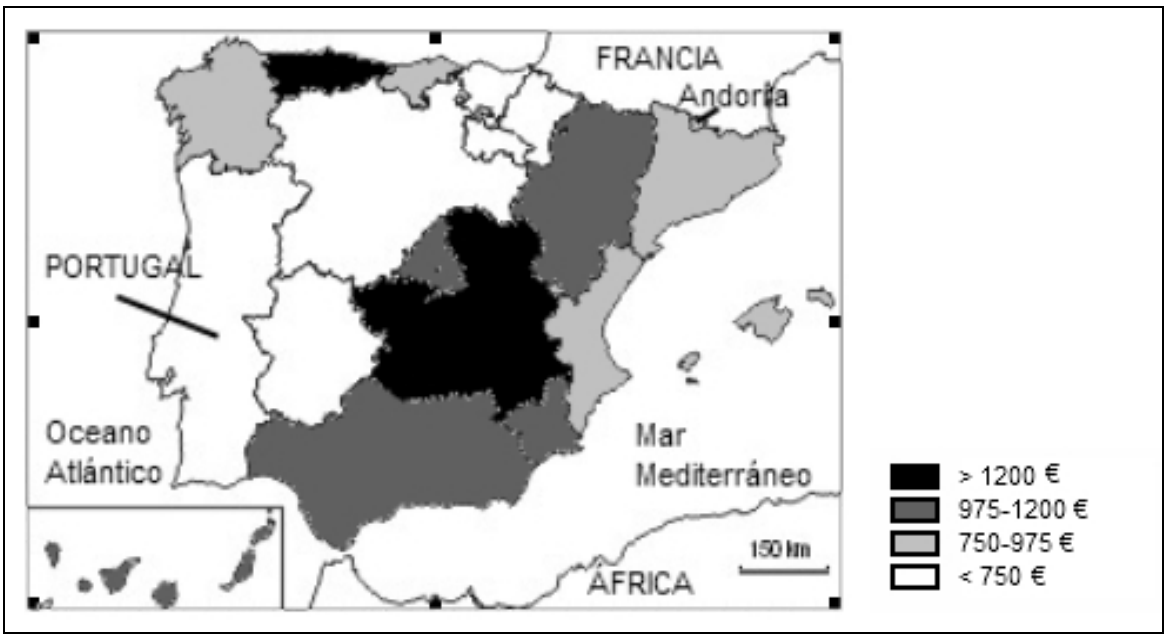

Fuente: elaboración propia a partir de EGATUR, 2014.

Figura 9

EVOLUCIÓN DEL GASTO MEDIO DIARIO POR PERSONA DE LOS TURISTAS INTERNACIONALES (2004-2013)

(en euros)

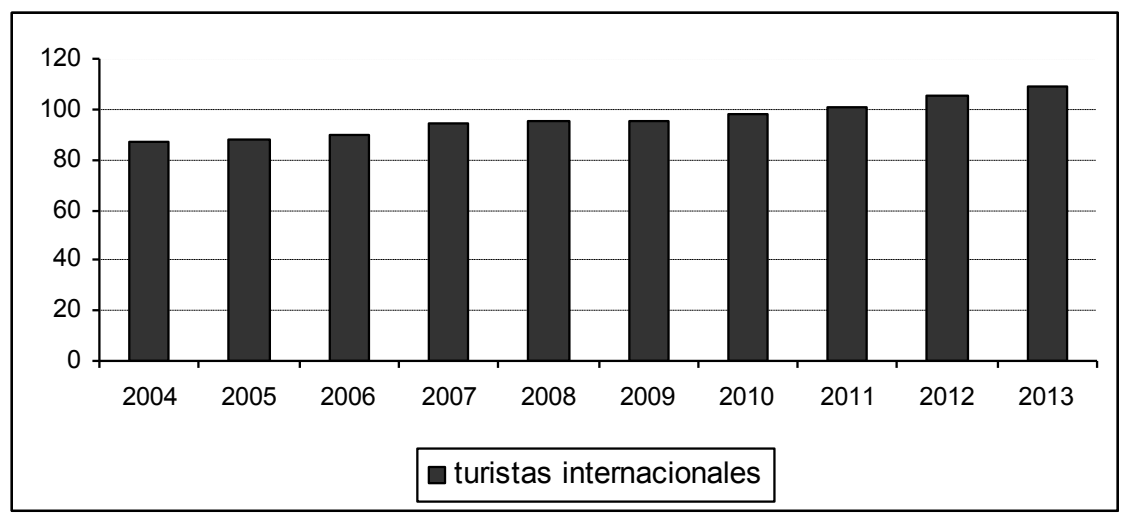

Fuente: elaboración propia a partir de EGATUR, 2014.

Por grupos de edad, los que más gastan diariamente en el destino, según datos de 2012, son los turistas internacionales entre 25 y 44 años (131,5 euros al día los hombres y 119,6 euros las mujeres; con una estancia media de 7,4 y 7,9 noches, respectivamente). Les siguen los de 45 a 64 años (117,9 euros al día los hombres y 107,3 euros las mujeres; con una estancia media de 8,3 y 9,3 noches, respectivamente). A continuación, los de 15 a 24 
años (102,1 euros al día los hombres y 93,3 euros las mujeres; con una estancia media de 10 y 10,9 noches, respectivamente). Luego los menores de 15 años (90,9 euros al día los hombres y 87,6 euros las mujeres; con una estancia media de 9,5 y 9,6 noches respectivamente). Finalmente, los que menos gastan son los mayores de 64 años (76,4 euros al día los hombres y 74,7 euros las mujeres; con una estancia media de 14 días en ambos casos). (EGATUR, 2014).

Los turistas extranjeros más jóvenes y los más mayores son los que menos gastan diariamente de media durante su estancia en España, debido a su menor poder adquisitivo. Los más mayores son los que pernoctan en el destino más noches, mientras que los que menos lo hacen son los que más gastan diariamente (los grupos de edad entre 25 y 64 años). En cuanto a las diferencias según el género, los hombres gastan de media diariamente más que las mujeres en todas las edades y también pernoctan menos tiempo, excepto los más mayores que permanecen en el destino las mismas noches.

Si se compara la evolución del número de turistas presentes en España (turistas internacionales, excursionistas y turismo interior de los propios residentes) con el gasto que estos han realizado en el período 2004-2013 (figura 10), se puede observar que, a pesar de las fluctuaciones en la cantidad de turistas, el gasto realizado ha seguido una progresión bastante constante.

\section{Figura 10}

EVOLUCIÓN DE LA CANTIDAD DE TURISTAS EN ESPAÑA Y DEL

GASTO TOTAL REALIZADO (2004-2013)(EN MILLONES DE EUROS)

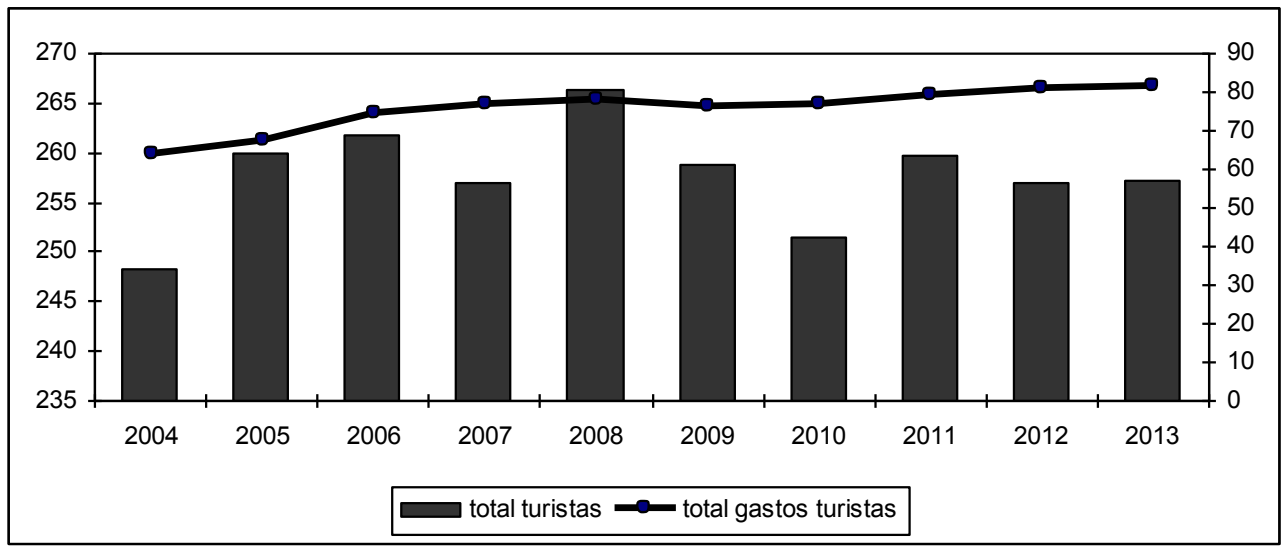

Fuente: elaboración propia a partir de FRONTUR, 2014; EGATUR, 2014; FAMILITUR, 2014.

Así pues, el turismo es una actividad económica fundamental para España, ya que en 2012 aportó el 10,9\% de su Producto Interior Bruto (PIB), con 1,9 millones de trabajadores afiliados a la Seguridad Social, lo que representa el 11,6\% del total de empleados del país. (INE, 2014). Para comprobar la magnitud de estas cifras basta con ver que Francia, país líder en este sector, el turismo aporta el 7,4\% de su PIB, con dos millones de empleos. (INSEE, 2014). 
Por otra parte, los resultados de la encuesta realizada por la FIA en 2009 indican que, de media, los cinco factores más importantes en el proceso de elección de un destino turístico vacacional son: la seguridad existente en el destino, el clima, la calidad de los alojamientos disponibles, la presencia de recursos naturales y el significado del viaje. Asimismo, para evaluar el grado de satisfacción alcanzado durante las vacaciones realizadas, los factores que más se valoran son: los recursos naturales del destino, el clima, el significado del viaje, la sensación de seguridad, las atracciones turísticas, la comida y la bebida, la calidad del alojamiento y la hospitalidad de la población local. Otros aspectos del destino menos valorados en el momento de la elección del viaje pero luego tenidos muy en cuenta en la evaluación de la satisfacción son: la accesibilidad al transporte público, la facilidad para realizar actividades deportivas y la vida nocturna. Por contra, los factores más presentes en el momento de la elección son: el coste de vida en el destino, el precio del transporte público, los servicios médicos y el entorno medioambiental.

Estos resultados y los de la encuesta del IET coinciden en que los aspectos más valorados en la satisfacción del turista respecto al viaje realizado son el paisaje, la confortabilidad del alojamiento, la oferta culinaria, el trato y atención recibida, el uso de idiomas y la seguridad del entorno.

\section{EVOLUCIÓN DEL TURISMO DE LITORAL EN ESPAÑA}

En este apartado se presenta de forma suscita la evolución de los destinos turísticos del litoral español que ha sido objeto de múltiples estudios. (Entre otros, Vera et al., 1997; Mundet, 1998; Garay, 2007; Priestley, 2007; Vera y Baños, 2010; Garay y Cànoves, 2011). El objetivo es poner de manifiesto como a partir de la importante concurrencia de turistas en las zonas litorales, se está afianzando el desarrollo de los destinos interiores próximos al litoral.

El turismo de litoral en España, se ha desarrollado siguiendo cinco fases. La primera, a finales del siglo XIX e inicios del XX, fue una etapa «proto-turista», con excursiones por la costa y aparición de bañistas. El aprovechamiento de los recursos naturales y la climatología del territorio español empezó a principios del siglo en el norte del país, en la Costa Cantábrica, pero con el tiempo se desplazó masivamente hacia el litoral mediterráneo y las islas. (García y Alburquerque, 2003).

Sin embargo, los conflictos socio-políticos, la inseguridad del país y las deficiencias en las infraestructuras y en los alojamientos provocaron que los turistas internacionales prefiriesen otros destinos europeos. Posteriormente, con la mejora económica y social española, en una etapa «pre-fordista», algunas zonas del litoral empezaron a ser destinos turísticos donde se comenzó a desarrollar un turismo de segundas residencias. Los países emisores predominantes eran Francia y Portugal, seguidos, con diferencia, por Estados Unidos, Gran Bretaña y Alemania, mientras que los destinos favoritos eran aquellos que disponían de un buen clima, una oferta cultural y un cierto exotismo para los visitantes, aunque poco a poco ya se empezaba a vislumbrar el comienzo del cambio hacia un modelo de sol y playa. (Moreno, 2007).

La Guerra Civil española, la Segunda Guerra Mundial y las postguerras frenaron bruscamente esta incipiente expansión turística en España, y hasta la década de 1950 no se producirá una ligera apertura de las fronteras, basada sobre todo en el interés comercial y monetario del Régimen franquista. El desarrollo económico español de la década de 1960, 
apoyó un nuevo modelo turístico «fordista», con un predominio de la estandarización, la uniformización y la pérdida de personalidad del producto turístico. Se inició la construcción de grandes hoteles en las zonas litorales mediterráneas y se reemprendió la expansión residencial anterior sin ningún tipo de planificación urbanística pero con un alto consumo del espacio. (Donaire, 2005).

Así, a principios de los años sesenta el turismo crecía de forma imparable, llegando a superar en el año 1970 el 15\% de cuota del mercado turístico mundial. Finalizando los años sesenta, el 74\% del turismo que acudía a España se dirigía a las zonas costeras, principalmente las mediterráneas. El turismo masivo comenzó a invadir las playas españolas y ser un gran captador de divisas. El modelo turístico de sol y playa se afianzó, con una concentración tanto geográfica (litoral) como estacional (verano) y una especialización en pocos, aunque potentes, mercados emisores: Reino Unido, Alemania y Francia. Sin embargo, en los 1970s, el turismo español sufrió una fuerte recesión como consecuencia de las sucesivas crisis económicas de la década, perdiendo cuatro millones y medio de turistas. (Moreno, 2007).

La cuarta fase (años 1980s y 1990s) fue de declive turístico como consecuencia de las crisis ocurridas en la anterior década. A pesar de ello, a mitad de los años 1980s se produce un pequeño auge turístico en España, debido, en parte, a la entrada en la Comunidad Europea. Sin embargo, la sobre-apreciación de la peseta redujo de forma considerable la competitividad de este destino, además de la aparición y consolidación de nuevos competidores del modelo «fordista» de sol y playa. A finales de este período empezó a reactivarse la actividad turística y se reinició la construcción de hoteles y segundas residencias en las zonas costeras. (Garay y Cànoves, 2011).

A finales del siglo XX empezó la quinta fase, llamada «post-fordista», con unos turistas con mayor poder adquisitivo y nuevas motivaciones y preferencias, iniciándose los vuelos aéreos «low cost» y multiplicándose la competencia de otros destinos turísticos con ofertas similares. (Priestley, 2007). A partir de 2008, y debido a la situación de crisis económica internacional, el turismo en general y en España en particular, experimentó un crecimiento del turismo de interior y una estabilización en el número de turistas extranjeros.

De este modo, influenciado por las preferencias de la demanda, las directrices y apoyos desde la administración central, los planes de negocio de los operadores turísticos internacionales, la especulación inmobiliaria y el auge de la hostelería, el producto turístico promovido en el litoral español se ha limitado en todos estos años al disfrute de determinados recursos naturales. (El sol y la playa). Este modelo ha dejado de lado la valorización de otros elementos de identidad presentes en estos territorios, tales como su patrimonio cultural, y ha provocado una situación de abigarramiento constructivo, muchas veces en zonas privilegiadas, y una congestión de turistas en los meses de temporada alta, que, en mucho casos, ha superado la capacidad de acogida de visitantes y la de sus infraestructuras conexas.

Este exceso de capacidad de carga en los destinos de litoral está afectando tanto a la experiencia percibida por el turista (y por consiguiente a su grado de satisfacción con la visita realizada) como a la sensación de pérdida relativa de calidad de vida de la comunidad local. Todo ello, junto con los profundos cambios producidos en los propios turistas, las nuevas tecnologías, la globalización y la intensa competividad entre destinos, hacen más evidente que este modelo turístico, que ha estado vigente durante el último medio siglo, se está agotando. (Ver la figura 11). 


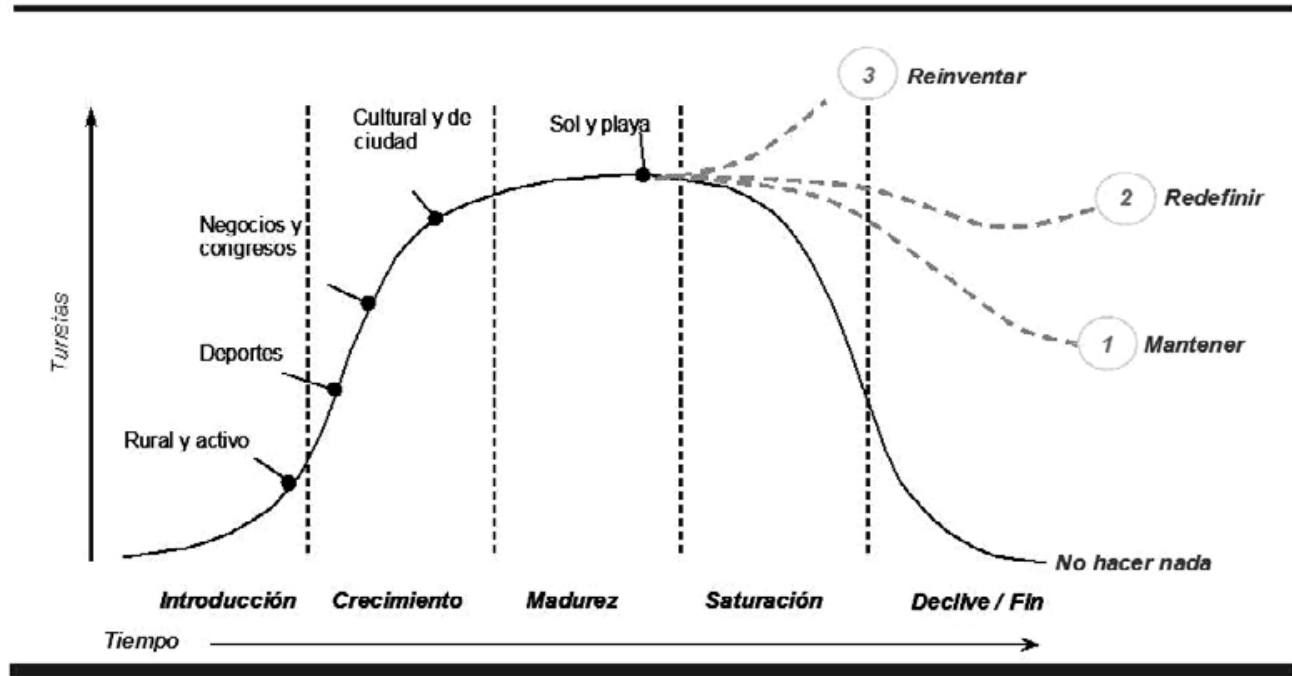

Fuente: elaboración propia a partir de Butler (1980) y Priestley (2007).

Sin embargo, esta situación también se presenta como un reto para la reconversión de la oferta turística en los destinos de litoral. Para ello, es necesario redefinir las políticas y estrategias mediante un nuevo modelo turístico que aspire a crear mayor valor añadido, sustentado en cuatro valores fundamentales e interrelacionados: la sostenibilidad, la calidad integral, la diferenciación y la diversificación del litoral y sus destinos turísticos. (IET, 2013).

No hay que olvidar que, en el caso de España, el turismo de litoral presenta una serie de ventajas, acordes con algunas de las motivaciones de los turistas para elegir este destino vacacional: una gran experiencia en la gestión de este tipo de turismo; una climatología y unos recursos naturales favorables; la buena calidad de las playas y de las instalaciones turísticas; y el reconocimiento de la marca turística de España, especialmente en Europa. Sin embargo, también presenta algunas debilidades a tener muy en cuenta: alta estacionalidad; gran dependencia de la demanda británica, alemana y francesa; fuerte presión medioambiental, demográfica y urbanística; mala imagen provocada en los turistas por los desarrollos macro-urbanísticos; la cada vez mayor escasez de recursos hídricos y el elevado consumo energético.

Ante esta situación, la diversidad cultural y geográfica del territorio español permite diseñar nuevos productos turísticos, en ocasiones como complemento al tradicional turismo de litoral y en otras como un producto alternativo. (Del Reguero, 1994). Así, uno de los más emergentes es el turismo cultural, el cual permite poner en valor turístico los recursos patrimoniales tangibles e intangibles de un territorio, teniendo en cuenta que dicho turismo se basa en «el traslado temporal de personas a una atracción cultural lejos de su residencia habitual con la intención de satisfacer sus necesidades culturales». (Richards, 1996). 


\section{EL TURISMO CULTURAL COMO OFERTA COMPLEMENTARIA EN LOS DESTINOS DE LITORAL}

Según los datos de TURESPAÑA (2012), el 52\% de los turistas internacionales que visitaron España en 2011 realizaron algún tipo de actividad cultural durante su visita. Dicha cifra se sitúa en el $61,7 \%$ en el caso de los turistas que vinieron principalmente por temas de ocio, recreo y vacaciones. De este modo, respecto al año anterior, creció un 9,6\% la cantidad de turistas internacionales que realizaron actividades culturales durante su estancia, con un crecimiento acumulado del 1,3\% durante el periodo 2005-2011, que es una cifra similar al crecimiento del total de turistas producido en dicho período $(+1,4 \%)$ e inferior al de turistas que acudieron por motivos de ocio $(+8,8 \%)$. (Ver figura 12$)$.

EVOLUCIÓN DE LAS VISITAS DE TURISTAS INTERNACIONALES A ESPAÑA (2005-2011) (EN MILLONES)

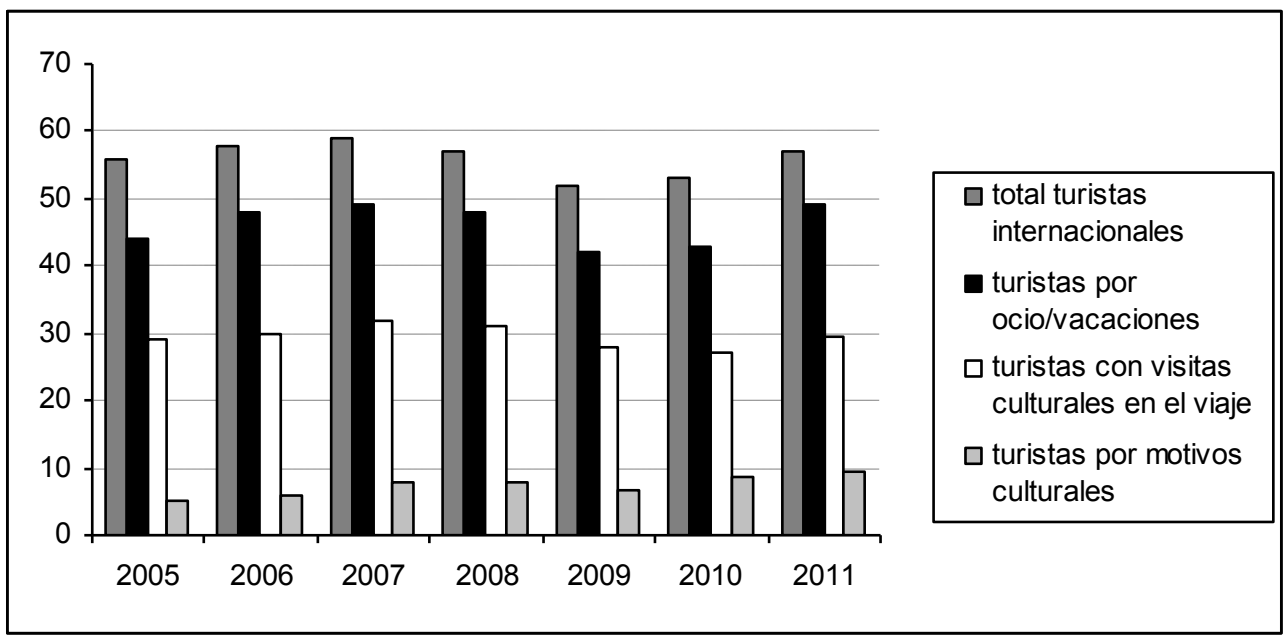

Fuente: TURESPAÑA, 2012.

Si se analiza cada motivo del viaje de forma separada, cabría destacar que el 70,2\% del total de turistas que realizaron viajes de estudios y el 54,4\% de los que viajaron por motivos de ocio, hicieron actividades culturales, mientras que sólo fue el 28,5\% en el caso de los que vinieron por trabajo o negocios. Por país de origen, el Reino Unido fue el principal emisor de turistas que en 2011 realizaron algunas actividades culturales durante su estancia en España (el 18,6\% del total de las entradas), seguido por Francia (el 15,6\%) y Alemania (el 15,1\%). Mención especial para los japoneses (el 85,9\% de los que vinieron realizó alguna actividad cultural) y los latinoamericanos (el 84,4\%). (TURESPAÑA, 2012).

Por grandes grupos de edad, el 43\% de los que tenían edades entre los 25 y 44 años (este grupo también predominó entre el total de turistas recibidos) hicieron visitas culturales, seguidos por el 30,4\% de los que tenían de 45 a 64 años. Si se examinan los grupos de edad por separado, destacan los turistas entre 15 y 24 años, pues el 57,8\% realizó visitas culturales durante su estancia, seguidos por los de 25 a 44 años, con el 53,2\%. Por comuni- 
dad autónoma de destino, Cataluña fue la principal receptora de los turistas que realizaron actividades culturales durante su estancia (el 30,1\%), seguida por Baleares (el 15,5\%) y Andalucía (el 15,1\%). Destacan los casos de Asturias, donde un 70,6\% de los turistas recibidos realizaron actividades culturales, y Madrid, con un 68\%. (TURESPAÑA, 2012).

El gasto realizado en estos viajes culturales ascendió a 30.500 millones de euros, lo que representó un $57,8 \%$ del gasto total en viajes y un $69,7 \%$ del gasto en viajes de ocio. En los viajes que incluyeron actividades culturales, el gasto medio por turista durante su estancia, incluyendo el transporte, fue de 1.034 euros (un - $0,7 \%$ menos que en 2010) y de 824 euros en los viajes donde no se realizaron estas actividades (un 0,9\% más que en 2010). A su vez, el gasto medio por turista que realizó alguna actividad cultural, sin tener en cuenta el transporte, fue de 763 euros (con un gasto medio diario de 77,6 euros y una estancia media de 9,8 días), mientras que el que no realizó ninguna actividad cultural tuvo un gasto medio de 488 euros (con un gasto medio diario de 57,9 euros y una estancia media de 8,4 días). (TURESPAÑA, 2012).

Sin embargo, muchos turistas además de consumir la cultura local como una actividad más durante su estancia, también realizan el viaje fundamentalmente por este motivo. Desde 2006, los viajes culturales han crecido todos los años, excepto en 2009, llegando este aumento en 2010 al 29,9\%, y manteniéndose en el $26 \%$ en 2011, triplicando el crecimiento del número de turistas. Así, según datos de TURESPAÑA (2012), en 2011 vinieron por este motivo 9,4 millones de turistas internacionales (el 17\% del total de los turistas recibidos).

El gasto realizado por estos turistas en 2011 fue de 8.500 millones de euros (un 43,3\% más que en el año anterior). Su gasto medio por persona durante la estancia fue de 654 euros excluyendo el transporte, lo que representó un gasto medio diario de 101 euros por persona. Esta cifra es muy superior al gasto medio diario por persona que realizaron los turistas que en dicho año vinieron por motivos no culturales (64 euros al día). (TURESPAÑA, 2012).

Por país de origen, el 20,2\% de los turistas que realizaron el viaje principalmente por motivos culturales eran franceses. Les siguieron los procedentes del Reino Unido (14,3\%), Italia $(13 \%)$, Alemania $(6,6 \%)$ y Holanda $(5,1 \%)$. Analizando de forma independiente cada uno de estos países, el 32,4\% de los turistas procedentes de Italia realizaron el viaje por motivos culturales, mientras que fue el $22,4 \%$ en el caso de Francia y solamente el 6,8\% en el de Alemania. Si se analiza de forma individual cada una de las comunidades autónomas de destino, destaca Madrid, donde el 35,3\% de los turistas acudió por motivos culturales, seguida por Cataluña (el 33,2\%), Andalucía (el 16,4\%) y Valencia (el 11,3\%), mientras que en Baleares solamente lo hizo el 2,4\%. (TURESPAÑA, 2012).

En cuanto a su perfil, el 58,3\% eran hombres y el 41,7\% mujeres. Predominaron los que procedían del Reino Unido, viajando en pareja por razones de ocio, mediante avión, sin paquete turístico y alojándose en un hotel. Por grupos de edad, los turistas entre los 25 y 44 años fueron los que más proporción de viajes culturales realizaron (el 20\%), seguidos por los más jóvenes (de 15 a 24 años) con el 19,1\%, mientras que los menos dados a realizar viajes culturales fueron los mayores de 64 años (el 13,2\%). (TURESPAÑA, 2012).

Ahora bien, el turismo cultural engloba gran variedad de tipologías (Bonet, 2003; Antón, 2005; Layuno, 2007; Vera y Baños, 2010). Desde las visitas a museos, ciudades 
y conjuntos históricos, monumentos y edificios singulares, monasterios e iglesias o yacimientos arqueológicos, hasta la gastronomía, enología, ferias, artesanía o festivales musicales; es decir, cualquier signo de identidad cultural de un territorio.

Tal como indica Spielberg (1995), hay cinco grados diferentes de motivación en el turismo cultural:

a) los que están muy motivados por la cultura

b) los que están motivados en parte por la cultura (viajan a un lugar, entre otras cosas, por las posibilidades culturales del mismo)

c) los que consideran la cultura como complemento a otra motivación principal (no se desplazan por una razón de índole cultural pero durante su estancia consumen este producto)

d) los que realizan este turismo de modo accidental (en principio no tienen la intención de realizar ninguna actividad cultural, pero de manera casual lo hacen)

e) los que no asisten a ninguna actividad cultural

Con el consumo del turismo cultural, el turista satisface su ansia de nuevas experiencias y amplía sus conocimientos, ayudando al desarrollo económico de unos territorios que ponen en valor sus recursos patrimoniales e impulsando un sentimiento de identidad local. En muchas ocasiones se trata de un modelo descompensado económicamente, que necesita importantes inversiones iniciales para la adecuación de las instalaciones, por lo que son necesarios apoyos financieros, en muchos casos con fondos públicos, en forma de subvenciones y patrocinios. (Layuno, 2007; Prat y Cànoves, 2012). Si nos fijamos en los lugares que visitan los turistas, vemos que las atracciones españolas más visitadas en 2012 fueron: Port Aventura, en Vilaseca (Tarragona), con 3,5 millones de visitantes; el Templo de la Sagrada Familia, en Barcelona, con 3,2 millones; y la Catedral de Santiago de Compostela, con tres millones. (IET, 2013).

Sin embargo, a pesar de su importancia, estos números distan mucho de los obtenidos en Francia, donde hay grandes focos de atracción turística («anchor points»), entre los que destacan Dysneyland Paris (con 16 millones de visitantes en 2012), el Museo del Louvre (9,4 millones), el Palacio de Versalles (con 7,3 millones) y la Tour Eiffel (con 6,3 millones). (INSEE, 2014). Al respecto, es remarcable que los monumentos turísticos más emblemáticos de Paris recibieron menos visitas que el parque temático de Disney. Así, la Torre Eiffel solamente recibió un 39,3\% de la cantidad de visitantes que fueron a dicho parque; mientras que el Arco del Triunfo recibió solamente un 10,6\%.

Analizando dos de las atracciones turístico-culturales más visitadas en España en estos últimos años, y situadas cerca de las grandes áreas turísticas de nuestro litoral, el complejo monumental de la Alhambra y Generalife, en Granada, y el Teatro-Museo Dalí, en Figueres (tabla 2), se observa que la Alhambra recibe principalmente turistas internacionales, tanto a nivel individual como en grupo, mientras que el Museo Dalí recibe mayoritariamente excursionistas, que pasan el día y no pernoctan en la ciudad de Figueres . Este hecho es explicable por la infinidad de zonas turísticas que existen en la Costa Brava y el hecho de la gran promoción del Teatro-Museo Dalí como un recurso de visita turística casi obligado en la zona, especialmente por los escolares franceses en viaje de estudios por nuestro país. 
Tabla 2

DETALLE DE LOS VISITANTES RECIBIDOS EN LAALHAMBRA-GENERALIFE Y EL TEATRO-MUSEO DALI (2012)

\begin{tabular}{|cr|c|c|}
\hline Visitantes (2012) & & $\begin{array}{c}\text { Alhambra y } \\
\text { Generalife }\end{array}$ & $\begin{array}{c}\text { Teatro-Museo } \\
\text { Dalí }\end{array}$ \\
\hline Individuales & & 1.439 .455 & 524.528 \\
\hline & Turistas internacionales & $78,83 \%$ & $1,55 \%$ \\
& Excursionistas & $16,24 \%$ & $90,45 \%$ \\
& Residentes & $4,93 \%$ & $8,00 \%$ \\
\hline Grupo & & 820.844 & 386.309 \\
\hline & Turistas internacionales & $68,59 \%$ & $0,00 \%$ \\
& Excursionistas & $30,40 \%$ & $99,50 \%$ \\
\hline Total 2012 & Residentes & $1,01 \%$ & $0,50 \%$ \\
\hline Total 2011 & & 2.260 .299 & 910.837 \\
\hline Crecimiento (\%) & & 2.310 .608 & 916.560 \\
\hline
\end{tabular}

Fuente: elaboración propia a partir de las Memorias del Patronato de la Alhambra y Generalife (2013) y de la Fundación Gala-Salvador Dalí (2013).

En cuanto al perfil socio-demográfico de estos visitantes, a partir de las encuestas realizadas en cada uno de ellos en el año 2012, se puede observar que, a nivel individual, en todos los casos predominan las personas con edades comprendidas entre 30 y 44 años; mientras que en la Alhambra, en el caso de los grupos, lo hacen los mayores de 60 años. (Detalle en la tabla 3).

En todos los casos son mayoría los visitantes con estudios superiores y situación laboral activa (trabajando o en paro). Si son turistas, suelen pernoctar en hoteles o similares (dos noches en Granada y una en Figueres). Las temporadas de más afluencia son Semana Santa y los meses de verano. Sin embargo, hay diferencias en cuanto a su lugar de procedencia, ya que en la Alhambra la mayoría procede de países de la Unión Europea distintos a España, mientras que en el Museo Dalí predominan los que vienen del resto del mundo, seguidos por los que lo hacen de los otros países de la Unión Europea. Por otra parte, el porcentaje de recomendación de la visita a futuros visitantes es superior al 78\% en todos los casos, mientras que el grado de satisfacción con la visita, supera el $80 \%$ en la Alhambra y el $62 \%$ en el Teatro-Museo Dalí.

Como se ha visto en este trabajo, el turismo cultural está creciendo en España, con unos consumidores de perfil medio-alto, relativamente jóvenes, que gastan más que la media de los turistas en general y que valorizan el patrimonio existente en el destino, obteniendo una alta satisfacción con la visita, prescribiéndola y repitiéndola varias veces (Prat, 2014; Troitiño, 2015). Por ello, el desarrollo y promoción de atracciones culturales de calidad en los destinos tradicionales del litoral, se presenta como una oportunidad para que dichos territorios presenten una oferta más atractiva a las nuevas motivaciones y demandas de los turistas, complementaria al sol y la playa, y que sirva para dar un salto cualitativo en la evolución turística de unos 
Tabla 3

PERFIL SOCIO-DEMOGRÁFICO DE LOS VISITANTES A LAALHAMBRA-GENERALIFE Y TEATRO-MUSEO DALI (2012)

\begin{tabular}{|c|c|c|c|c|}
\hline \multicolumn{2}{|l|}{ Perfil } & \multirow{2}{*}{$\begin{array}{c}\text { Alhambra y } \\
\text { Generalife } \\
\text { Visitantes } \\
\text { individuales }\end{array}$} & \multirow{2}{*}{$\begin{array}{l}\text { Alhambra y } \\
\text { Generalife } \\
\begin{array}{c}\text { Visitantes en } \\
\text { grupo }\end{array}\end{array}$} & \multirow{2}{*}{$\begin{array}{c}\text { Teatro-Museo } \\
\text { Dalí }\end{array}$} \\
\hline & & & & \\
\hline \multirow[t]{5}{*}{ Edad } & $<15$ años & $0,26 \%$ & $0 \%$ & $4 \%$ \\
\hline & 15-29 años & $26,82 \%$ & $16,10 \%$ & $16 \%$ \\
\hline & 30-44 años & $31,44 \%$ & $16,11 \%$ & $44 \%$ \\
\hline & 45-60 años & $31,31 \%$ & $28,37 \%$ & $23 \%$ \\
\hline & $>60$ años & $10,17 \%$ & $39,42 \%$ & $13 \%$ \\
\hline \multirow[t]{3}{*}{ Nivel educativo } & Medio & $25,67 \%$ & $32,03 \%$ & $16 \%$ \\
\hline & Superior & $65,51 \%$ & $52,57 \%$ & $66 \%$ \\
\hline & Resto & $8,82 \%$ & $15,40 \%$ & $18 \%$ \\
\hline \multirow[t]{4}{*}{ Situación laboral } & Activos & $71,53 \%$ & $50,97 \%$ & $69 \%$ \\
\hline & Jubilados & $10,07 \%$ & $31,71 \%$ & $7 \%$ \\
\hline & Estudiantes & $15,50 \%$ & $13,41 \%$ & $20 \%$ \\
\hline & Otros & $2,90 \%$ & $3,91 \%$ & $4 \%$ \\
\hline \multirow[t]{4}{*}{ Procedencia } & Misma comunidad & $7,38 \%$ & $4,09 \%$ & $11 \%$ \\
\hline & Resto España & $21,42 \%$ & $23,65 \%$ & $10 \%$ \\
\hline & Unión Europea & $48,69 \%$ & $48,78 \%$ & $37 \%$ \\
\hline & Resto mundo & $22,51 \%$ & $23,48 \%$ & $42 \%$ \\
\hline \multirow[t]{4}{*}{ Alojamiento } & Hotel & $63,66 \%$ & $84,17 \%$ & $52 \%$ \\
\hline & Apartamento & $10,09 \%$ & $1,95 \%$ & $16 \%$ \\
\hline & Vivienda & $19,92 \%$ & $4,44 \%$ & $13 \%$ \\
\hline & Otros & $6,33 \%$ & $9,44 \%$ & $19 \%$ \\
\hline \multirow[t]{3}{*}{ Pernoctaciones } & 1 noche & $10,24 \%$ & $29,15 \%$ & nd \\
\hline & 2 noches & $37,90 \%$ & $19,60 \%$ & nd \\
\hline & $>2$ noches & $30,72 \%$ & $19,85 \%$ & nd \\
\hline Recomendación visita & & $81 \%$ & $83 \%$ & $78 \%$ \\
\hline $\begin{array}{l}\text { Alto grado } \\
\text { satisfacción visita }\end{array}$ & & $87 \%$ & $89 \%$ & $62 \%$ \\
\hline Meses más aforo & & $\begin{array}{l}\text { abril, mayo, } \\
\text { agosto }\end{array}$ & $\begin{array}{l}\text { abril, mayo, } \\
\text { agosto }\end{array}$ & $\begin{array}{c}\text { abril, julio, } \\
\text { agosto, } \\
\text { septiembre }\end{array}$ \\
\hline
\end{tabular}

Fuente: elaboración propia a partir de las Memorias del Patronato de la Alhambra y Generalife (2013) y de la Fundación Gala-Salvador Dalí (2013). 
destinos con una alta saturación y algunos con un cierto declive. En definitiva abogar por la diversificación del producto turístico de sol y playa y potenciar los destinos turísticos interiores (Cànoves y Blanco-Romero, 2011) a base del producto de turismo cultural debe ser una apuesta de futuro clave para el mantenimiento del producto sol y playa, que cada vez más se complementa con otros nuevos productos, fruto de un turista más poliédrico, exigente e informado.

\section{CONCLUSIONES}

En este artículo, después de repasar la situación actual del turismo mundial, en general, y de España, en particular, y ver como ha evolucionado el turismo de litoral español a un modelo uniforme de sol y playa, provocando la saturación de algunos destinos, con sus fortalezas y debilidades, se ha presentado el turismo cultural como un producto complementario que puede ayudar a revitalizar estos destinos, en un escenario de calidad, competitividad y sostenibilidad.

El turismo cultural apuesta por un producto personalizado y de calidad, que, aunque inicialmente necesita importantes inversiones en infraestructuras y servicios, da como resultado unos ingresos por turista superiores a la media, ya que, junto a las visitas a museos, monumentos y otros puntos de atracción cultural, el visitante suele manifestar un alto interés por consumir otros productos locales, mantener contacto con la población local y conocer sus tradiciones. Sin embargo, es aún un producto turístico que, en general, todavía no es sinónimo de sostenibilidad económica, exceptuando los casos en los que existe un fuerte polo de atracción de turistas como las dos atracciones aquí presentadas. De esta manera, en el presente artículo se ha comprobado la hipótesis inicial, ya que España también se está posicionando como un importante destino de turismo cultural, que ayuda a la diversificación turística de los territorios, y a la revitalización de los destinos de litoral maduros tradicionalmente orientados al producto sol y playa.

En este contexto, destaca la satisfacción obtenida por el turista con el consumo de productos culturales durante su viaje, ya que el componente emocional adquiere extraordinaria importancia dentro de la experiencia realizada. Por ello, los destinos tradicionales de litoral, si quieren diferenciarse de sus competidores y seguir desarrollándose en el futuro, deben ser capaces de ofrecer, a través de una serie de actividades complementarias, una amalgama de emociones y experiencias que permitan a los turistas no solamente disfrutar del sol y la playa sino también de poder visitar espacios próximos donde el elemento cultural sea relevante y no finito: Es decir, se trata de conseguir el retorno al destino, de manera que la experiencia demande una nueva visita.

Además de los beneficios económicos, el desarrollo de este tipo de turismo supone un efecto positivo sobre los destinos, ya que contribuye al mantenimiento, preservación y protección de su patrimonio cultural, en muchos casos olvidado por no tener gran rentabilidad económica o no haberla explorado suficientemente, y ayuda a preservar la identidad y la autoestima del territorio. Por ello, en un escenario donde el turismo y la cultura interactúan, beneficiándose mutuamente, es necesaria la colaboración y coordinación entre los distintos agentes implicados (administraciones públicas, empresarios y asociaciones locales, comunidad local), ya que esta actividad les supondrá un factor de regeneración y revitalización de sus municipios y de su imagen externa e interna, y de vertebración y reequilibrio del territorio. 
El modelo francés, que impregna sus territorios interiores de elementos y productos susceptibles de tener valor turístico y que acoge la diversificación y la segmentación del producto turístico, debe servir de ejemplo en nuestro país para conseguir ofrecer al turista y al visitante de un sólo día unas experiencias y unos productos turístico-culturales que sean tan o, si cabe, más atractivos que el sol y la playa. O mejor dicho, hacer del sol y la playa, junto con los territorios colindantes, una permeabilización turística que permita diseminar los beneficios económicos del turismo.

\section{BIBLIOGRAFÍA}

ANTON, S. (2005): «De los procesos de diversificación y cualificación a los productos turísticos emergentes. Cambios y oportunidades en la dinámica reciente del turismo litoral». Papeles de Economía Española, ${ }^{\circ}$ 102, 316-332.

ANTZCAK, M. y LE GARREC, M.A. (2008): «Le tourisme international en France en 2007». Tourisme Infos Stat, $\mathrm{n}^{\circ}$ 2008-5.

BONET, L. (2003): «Cultural Tourism», en TOWSE, R. (Ed.). Handbook of Cultural Economics. Glos. Edward Elgar, 187-193.

BUTLER, R.W. (1980): «The concept of tourism area cycle of evolution: implications for management of resources». Canadian Geographer, $\mathrm{n}^{\circ} 24$ (1), 5-12.

CANOVES, G. y BLANCO-ROMERO, A. (2011) «Turismo religioso en España: ¿La gallina de los huevos de oro? Una vieja tradición, versus un turismo emergente». Cuadernos de Turismo, $\mathrm{n}^{\circ} 27,115-131$. Universidad de Murcia.

DAUPHIN, L.; LE GARREC, M.A. y TARDIEU, F. (2007): Les vacances des Français depuis 40 ans. Paris. DSPES - Direction du Tourisme, Ministère de l'Économie, de l'Industrie et de l'Emploi.

DEL REGUERO, M. (1994): Ecoturismo. Nuevas formas de turismo en el espacio rural. Barcelona. Editorial Bosch.

DONAIRE, J. A. (2005): «La lògica espacial del turisme a la Costa Brava», en Debat Costa Brava. Un futur sostenible. Girona. COAC, 218-225.

EGATUR (2014): Encuesta del gasto turístico. Informe anual 2012. Madrid. Instituto de Turismo de España Disponible en http://www.iet.tourspain.es/es-ES/estadisticas/frontur/ Anuales/Movimientos\%20Tur\%C3\%ADsticos\%20en\%20Fronteras\%20(Frontur)\%20 y\%20Encuesta\%20de\%20Gasto\%20Tur\%C3\%ADstico\%20(Egatur)\%202012.pdf

FAMILITUR (2014): Informe anual 2012. Madrid. Instituto de Turismo de España. Disponible en http://www.iet.tourspain.es/es-ES/estadisticas/familitur/Anuales/Informe\%20 anual\%20de\%20Familitur.\%20A\%C3\%B10\%202012.pdf

FIA (2009): What do you consider important when choosing a destination for your summer holiday?. iTest Overall Results. Paris. FIA Editions. Disponible en http://www.fiaregion1. com/download/publications/itestoverall_results_report_1_4.pdf

FRONTUR (2014): Movimientos turísticos en fronteras. Informe anual 2013. Madrid. Instituto de Turismo de España. Disponible en http://www.iet.tourspain.es/WebPartInformes/ paginas/rsvisor.aspx ?ruta $=\% 2 \mathrm{fFrontur} \% 2 \mathrm{fEstructura} \% 2 \mathrm{fAnual} \% 2 \mathrm{fEntradas}+\mathrm{de}+\mathrm{visitant}$ es+seg\%u00fan+tipolog\%u00eda.+-+Ref.201\&par=1\&idioma=es-ES\&anio=2013 
FRONTUR (2013): Nota de coyuntura. Diciembre 2013. Disponible en http://www.iet.tourspain.es/es-ES/estadisticas/frontur/mensuales/Nota\%20de\%20coyuntura\%20de\%20Frontur.\%20Diciembre\%202013.pdf

FUNDACIÓN GALA-SALVADOR DALÍ (2013): Memoria 2012. Figueres. Fundación Gala-Salvador Dalí. Disponible en https://www.salvador-dali.org/media/upload/arxius/ memories/Memoria-2012-cat-esp.pdf

GARAY, L. (2007): «El Ciclo de Evolución del Destino Turístico. Una aproximación al desarrollo histórico del turismo en Cataluña». Tesis doctoral. Bellaterra. Universitat Autònoma de Barcelona.

GARAY, L. y CÀNOVES, G. (2011): «Life cycles, stages and tourism history. The Catalonia (Spain) experience». Annals of Tourism Research, $\mathrm{n}^{\circ} 38$ (2), 651-671.

GARCÍA, A. y ALBURQUERQUE, F.J, (2003): «El turismo cultural y el de sol y playa: ¿sustitutivos o complementarios?». Cuadernos de Turismo, $\mathrm{n}^{\circ}$ 11, 97-105.

HABITUR (2012). Encuesta de hábitos turísticos. Informe anual 2011. Madrid, Instituto de Turismo de España. Disponible en http://www.iet.tourspain.es/es-ES/estadisticas/otrasestadisticas/habitur/anuales/Informe\%20Habitur\%202011.pdf

IET (2013): Balance del Turismo en España. Año 2012. Madrid. Instituto de Estudios Turísticos.

INE (2014): Cuenta satélite del turismo de España. Base 2008. Madrid. Instituto Nacional de Estadística Disponible en http://www.ine.es/jaxi/tabla.do?path=/t35/p011/2012/ 10/\&file $=01001 . p x \&$ type $=$ pcaxis $\& \mathrm{~L}=0$

INSEE (2014): Publications et statistiques pour la France ou les régions. Paris. Disponible en http://www.insee.fr/fr/themes/theme.asp?theme=13\&sous_theme=5

KESTER, J.G.C. (2014): «2013 International Tourism Results and prospects for 2014». UNWTO News Conference. Madrid (20 de enero de 2014).

LAYUNO, M.A. (2007): «El museo más allá de sus límites. Procesos de musealización en el marco urbano y territorial». Oppidum, $\mathrm{n}^{\circ} 3,133-164$.

MORENO, A. (2007): Historia del Turismo en España en el s. XX. Madrid. Síntesis.

MUNDET, Ll. (1998): «L'evolució dels models de turismo litoral. El Regne Unit, la Costa Brava i Cuba». Tesis doctoral. Girona. Universitat de Girona.

OMT (2014): Panorama del turismo internacional 2013. Madrid. Organización Mundial del Turismo. Disponible en http://dtxtq4w60xqpw.cloudfront.net/sites/all/files/pdf/unwto_ highlights13_sp_lr_0.pdf

PATRONATO DE LA ALHAMBRA Y GENERALIFE (2013): Datos de la actividad turística, educativa y cultural en el conjunto monumental de la Alhambra y Generalife. Año 2012. Granada. Consejería de Cultura y Deporte. Junta de Andalucía. Disponible en http://www.alhambra-patronato.es/fileadmin/PAG/comunicacion/servicios_generales/ notas_prensa/Balance_2012.pdf

PRAT, J.M. y CÀNOVES, G. (2012): «El turismo cultural como oferta complementaria en los destinos de litoral. El caso de la Costa Brava (España)». Revista de Investigaciones Geográficas, $\mathrm{n}^{\circ}$ 79, 119-135.

PRAT, J.M. (2014): «Nuevos planteamientos y nuevas motivaciones en la elección de destinos de turismo cultural-urbano homosexual: el Festival Circuit de Barcelona». Cuadernos de Turismo, $\mathrm{n}^{\circ} 33,311-334$. 
PRIESTLEY, G. (2007): «Sostenibilidad, ciclo de vida y desarrollo de los destinos turísticos: hacia un nuevo modelo del turismo español», en PRIESTLEY, G. y LLURDÉS, J.C. (dir.) Estrategia y gestión del turismo en el municipio. Bellaterra. Escola Universitària de Turisme i Direcció Hotelera - UAB, 29-42.

RICHARDS, G. (1996): Cultural Tourism in Europe. Wallingford. CABI.

SPIELBERG, T. (1995): «Cultural tourism and business opportunities for museums and heritages sites». Tourism Management, $\mathrm{n}^{\circ} 16$ (5).

TNS-SOFRES (2008): Enquête sur les visiteurs de l'étranger (EVE) 2007. Paris. Direction du Tourisme.

TROITIÑO, L. (2015): «La dimensión turística del patrimonio cultural de la ciudad de Lorca (Murcia)». Cuadernos de Turismo, $n^{\circ} 36,389-414$.

TURESPAÑA (2012): Turismo cultural de turistas extranjeros. Año 2011. Madrid. Instituto de Turismo de España. Disponible en http://www.tourspain.es/es-es/inteligenciamercados/EstudiosPublicaciones/Documentos\%20Estudios \%20de\%20Producto\%200tros/ Estudio\%20de\%20Producto\%20de\%20Turismo\%20Cultural.pdf

VERA, J.F. y BAÑOS, C.J. (2010): «Renovación y reestructuración de los destinos turísticos consolidados del litoral: las prácticas recreativas en la evolución del espacio turístico». Boletín de la Asociación de Geógrafos Españoles, $\mathrm{n}^{\circ}$ 53, 329-353.

VERA, J.F.; LÓPEZ PALOMEQUE, F.; MARCHENA, M. y ANTÓN, S. (1997): Análisis Territorial del Turismo. Barcelona. Ariel.

WILLIAMS, C. y BUSWELL, J. (2003): Service Quality in Leisure and Tourism. Wallingford. CABI. 